\begin{tabular}{|c|c|c|}
\hline Case Reports in & \multicolumn{2}{|c|}{ Case Rep Gastroenterol 2018;12:722-728 } \\
\hline Gastroenterology & $\begin{array}{l}\text { DOI: 10.1159/000492215 } \\
\text { Published online: November 28, } 2018\end{array}$ & $\begin{array}{l}\text { (c) } 2018 \text { The Author(s) } \\
\text { Published by S. Karger AG, Basel } \\
\text { www.karger.com/crg }\end{array}$ \\
\hline & $\begin{array}{l}\text { This article is licensed under the } \mathrm{Cr} \\
\text { International License (CC BY-NC) (ht } \\
\text { Usage and distribution for commercial }\end{array}$ & $\begin{array}{l}\text { nons Attribution-NonCommercial } 4.0 \\
\text { ger.com/Services/OpenAccessLicense). } \\
\text { uires written permission. }\end{array}$ \\
\hline
\end{tabular}

\title{
Endoscopic Ultrasound-Guided Gallbladder Drainage for Aberrant Right Posterior Duct Obstruction Developing after Placement of a Covered Self- Expandable Metallic Stent in a Patient with Distal Biliary Obstruction
}

Yuko Suzuki Yusuke Hashimoto Taro Shibuki Motoyasu Kan Gen Kimura Kumiko Umemoto Kazuo Watanabe Mitsuhito Sasaki Hideaki Takahashi Hiroshi Imaoka Izumi Ohno Shuichi Mitsunaga Masafumi Ikeda

Department of Hepatobiliary and Pancreatic Oncology, National Cancer Center Hospital East, Kashiwa, Japan

\section{Keywords}

Endoscopic ultrasound-guided gallbladder drainage - Anatomical anomaly of the bile duct . Aberrant hepatic duct · Biliary drainage

\section{Abstract}

Endoscopic ultrasound-guided gallbladder drainage (EUS-GBD) has been utilized as an alternative endoscopic technique for patients with acute cholecystitis. In addition to EUS-guided hepaticogastrostomy and EUS-guided cystogastrostomy, EUS-GBD has been reported as being useful for biliary drainage in cases with distal malignant biliary obstruction instead of conventional endoscopic retrograde cholangiopancreatography. We present a case of successful EUS-GBD for malignant obstruction of an aberrant hepatic duct draining directly into the cystic duct.

(C) 2018 The Author(s)

Published by S. Karger AG, Basel 


\section{Case Reports in Gastroenterology}

Case Rep Gastroenterol 2018;12:722-728

DOI: $10.1159 / 000492215$

(c) 2018 The Author(s). Published by S. Karger AG, Basel www.karger.com/crg

Suzuki et al.: EUS-GBD for Aberrant Right Posterior Duct Obstruction Developing after Placement of a Covered SEMS in a Patient with Distal Biliary Obstruction

\section{Introduction}

Endoscopic ultrasound-guided gallbladder drainage (EUS-GBD) has been reported as an alternative endoscopic technique for acute cholecystitis in nonsurgical candidates with inoperable malignant diseases or multiple comorbidities. According to the literature, EUS-GBD is a clinically effective technique with few complications. EUS-GBD has been shown to allow successful biliary drainage in cases of distal malignant biliary obstruction and after failed conventional endoscopic retrograde cholangiopancreatography (ERCP), when the gallbladder communicates with the proximal common bile duct [1]. On the other hand, aberrant hepatic duct (AHD) is a rare anatomical anomaly of the bile duct branch, assuming segmental biliary drainage of the liver and draining directly into the extrahepatic bile duct, cystic duct, or gallbladder $[2,3]$. However, EUS-guided biliary drainage in a patient with AHD has not been reported before. We present a case of successful EUS-GBD in a patient with malignant obstruction of an AHD in the posterior segment of the right hepatic lobe draining directly into the cystic duct.

\section{Case Presentation}

The patient was a 70-year-old female with jaundice diagnosed as having locally advanced pancreatic cancer, who had undergone endoscopic palliative biliary drainage using a self-expandable metallic stent (SEMS) for obstruction of the distal bile duct prior to chemotherapy. Palliative chemotherapy was started after successful resolution of the jaundice. One month after the SEMS placement, the patient presented with complaints of fever and generalized fatigue. Laboratory evaluation revealed elevated levels of serum alkaline phosphatase and serum C-reactive protein $(1,155 \mathrm{IU} / \mathrm{L}, 8.71 \mathrm{mg} / \mathrm{dL}$; upper limit of normal for serum alkaline phosphatase and serum C-reactive protein: $359 \mathrm{IU} / \mathrm{L}$ and $0.30 \mathrm{mg} / \mathrm{dL}$, respectively). The patient was suspected as having acute septic cholangitis and was initiated on treatment with intravenous antibiotics. Contrast-enhanced abdominal computed tomography (CT) showed segmental cholangitis in the right posterior segment of the right hepatic lobe, with enhancement of the liver parenchyma and the posterior hepatic duct draining into the cystic duct and thence into the gallbladder, indicative of AHD (Fig. 1). This was considered to have occurred because of a blockade of the cystic duct by the indwelling SEMS. We therefore opted for EUSGBD for biliary drainage of the posterior intrahepatic bile duct instead of percutaneous transhepatic gallbladder drainage after obtaining the patient's consent. A linear echoendoscope (GF-UCT-260; Olympus, Tokyo, Japan) was used for the procedure, which revealed dilatation of the posterior branch of the bile duct and cystic duct and enlargement of the gallbladder. The gallbladder was punctured with a 19-gauge EUS-FNA needle (Expect; Boston Scientific, MA, USA) from the posterior duodenal bulb with a 0.025 -inch guidewire (Visiglide 2; Olympus), and a fistula was created with a 6-Fr diathermic dilator (Endo-Flex; Voerde, Germany). Finally, a covered SEMS (Wallflex; Boston Scientific, Marlborough, MA, USA) was placed for cholecystoduodenostomy, and an indwelling double pig-tail plastic stent (Olympus) was placed through the SEMS to prevent migration (Fig. 2). The procedure was uneventful. No postprocedural complications occurred, and the patient recovered immediately from the cholangitis. After successful EUS-GBD for the AHD biliary drainage, the patient could continue palliative chemotherapy with no further episodes of cholangitis or cholecystitis until the patient died of cancer 17 months later. 


\section{Discussion}

AHD is defined as an anatomical anomaly of the bile duct branch, assuming segmental biliary drainage of a section or segment of the liver and direct drainage into the extrahepatic bile duct, cystic duct, or gallbladder. The estimated frequency of AHD in the general population is approximately $0.8-18 \%[2,3]$. AHD has several variations, is observed mostly in the right hepatic lobe, and has been classified according to the pattern of confluences by several researchers [4-6]. A rare branch that drains into the gallbladder or cystic duct is called cholecystohepatic duct, which was first reported by Neuhof and Bloomfield in 1945 [7] and accounts for $0.7-2.3 \%$ of all cases [8].

Acute cholecystitis is one of the postprocedural complications of covered SEMS placement in the distal common bile duct. According to previous reports, covered SEMS placement in the common bile duct with stones in the gallbladder carries an elevated risk of acute cholecystitis. SEMS placement over the cystic duct confluence and tumor involvement of the orifice of the cystic duct, regardless of the type of SEMS, have been identified as independent risk factors for the development of acute cholecystitis after SEMS placement $[9,10]$.

In our case, the right posterior intrahepatic bile duct drained directly into the cystic duct, which was blocked by the previous placement of an indwelling covered SEMS for distal biliary obstruction. We considered that the patient was at a high risk of developing cholecystitis because abdominal CT showed infiltration of the cystic duct by pancreatic cancer, and there were gallbladder stones. Acute cholecystitis was not yet evident on physical examination or on imaging examinations because of compensatory enlargement of the gallbladder for drainage of the right posterior segment. For anatomical reasons and technical ease, we opted to perform EUS-GBD instead of EUS-guided hepaticogastrostomy for drainage of the right AHD.

The AHD in our patient was recognized based on the appearance of dilatation of both the cystic duct and the right posterior intrahepatic bile duct on abdominal CT; however, in retrospect, the AHD could be vaguely visualized even on the initial magnetic resonance imaging performed at the time of diagnosis of the pancreatic cancer (Fig. 3). During the first ERCP, we had better obtain a full cholangiogram before the SEMS was placed, although the contrast between the right posterior intrahepatic bile duct and the common bile duct seemed poor. Simultaneous endoscopic retrograde gallbladder drainage or cystic duct drainage could have been among the treatment options, if the AHD had been recognized during the first ERCP.

In conclusion, we report a case in which we accomplished successful biliary drainage from an aberrant posterior intrahepatic bile duct by EUS-GBD. EUS-guided drainage is one of useful techniques, although the presence of an AHD poses an anatomical challenge in patients requiring biliary drainage.

\section{Statement of Ethics}

The authors have no ethical conflicts to disclose.

\section{Disclosure Statement}

The authors state that they have no conflicts of interest to disclose. 


\section{References}

1 Imai H, Kitano M, Omoto S, Kadosaka K, Kamata K, Miyata T, et al. EUS-guided gallbladder drainage for rescue treatment of malignant distal biliary obstruction after unsuccessful ERCP. Gastrointest Endosc. 2016 Jul;84(1):147-51.

2 Michels NA. The hepatic, cystic and retroduodenal arteries and their relations to the biliary ducts with samples of the entire celiacal blood supply. Ann Surg. 1951 Apr;133(4):503-24.

3 Okada K, Tamio T, Yagi A. Studies with ERCP in cases with anomalies of biliary tract, with special references of cystic duct. Jpn J Gastroenterol Surg. 1981 Aug;14(8):1197-203.

4 Hayes MA, Goldenberg IS, Bishop CC. The developmental basis for bile duct anomalies. Surg Gynecol Obstet. 1958 Oct;107(4):447-56.

5 Flint E. Abnormalities of the right hepatic, cystic, and gastroduodenal arteries, and of the bile-ducts. BJS. 1923 Apr;10(40):509-19.

6 Miyakawa T. The clinical significance of accessory bile duct: evaluation with PTC and ERCP. Jpn J Gastroenterol Surg. 1980 Jun;13(6):451-8.

7 Neuhof H, Bloomfield S. The Surgical Significance of an Anomalous Cholecystohepatic Duct: case Reports Ann Surg. 1945 Aug;122(2):260-5.

8 Hamada T, Matsuzaki S, Noguchi D, Taoka H. Cholecystectomy with reconstruction involving anastomosis of the B5-cystic duct with a cysthepatic duct. J Japan Surg Assoc. 2014 Apr;75(4):1050-55.

9 Shimizu E, Kikuyama M, Hirai R, Ogawa K. Acute cholecystitis after expandable metal stent placement for malignant biliary obstruction. J Japan Biliary Assoc. 2006 Feb;20(2):142-6.

10 Isayama H, Kawabe T, Nakai Y, Tsujino T, Sasahira N, Yamamoto N, et al. Cholecystitis after metallic stent placement in patients with malignant distal biliary obstruction. Clin Gastroenterol Hepatol. 2006 Sep;4(9):1148-53. 


\section{Case Reports in Gastroenterology}

\begin{tabular}{l|l}
\hline Case Rep Gastroenterol 2018;12:722-728 \\
\hline DOI: 10.1159/000492215 & $\begin{array}{l}\text { ○ 2018 The Author(s). Published by S. Karger AG, Basel } \\
\text { www.karger.com/crg }\end{array}$ \\
\hline
\end{tabular}

Suzuki et al.: EUS-GBD for Aberrant Right Posterior Duct Obstruction Developing after Placement of a Covered SEMS in a Patient with Distal Biliary Obstruction
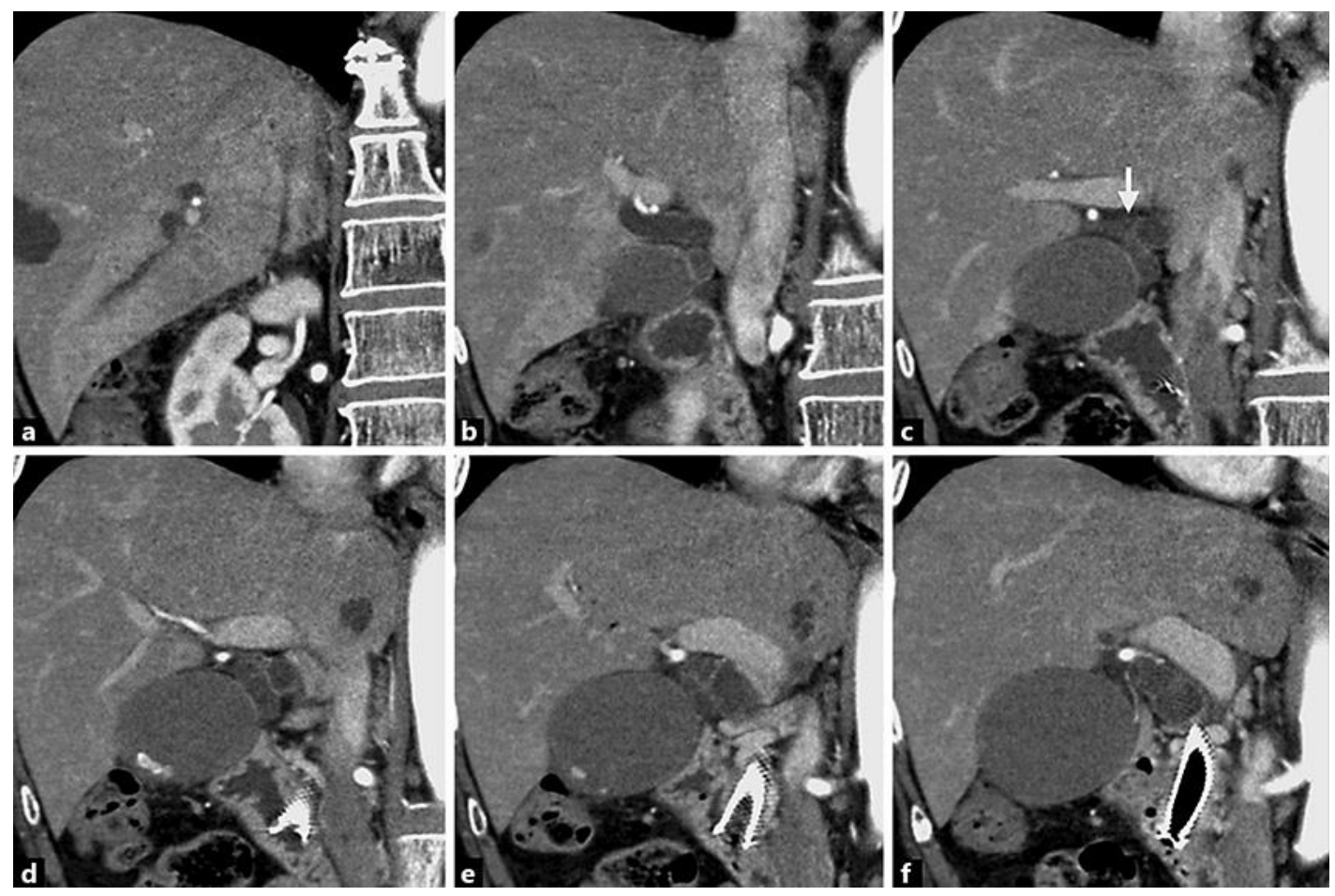

Fig. 1. Abdominal CT showing cholangitis in the right posterior segment of the right hepatic lobe, with enhancement of the liver parenchyma (a). Dilated posterior intrahepatic bile duct draining directly into the cystic duct and thence into the gallbladder (a-e). Confluence of the AHD with the cystic duct (c, arrow). Stones are observed within the gallbladder $(\mathbf{d}, \mathbf{e})$. The cystic duct is blocked by the presence of an indwelling covered SEMS (f). 


\section{Case Reports in Gastroenterology}

Case Rep Gastroenterol 2018;12:722-728

DOI: $10.1159 / 000492215$

(c) 2018 The Author(s). Published by S. Karger AG, Basel www.karger.com/crg

Suzuki et al.: EUS-GBD for Aberrant Right Posterior Duct Obstruction Developing after Placement of a Covered SEMS in a Patient with Distal Biliary Obstruction
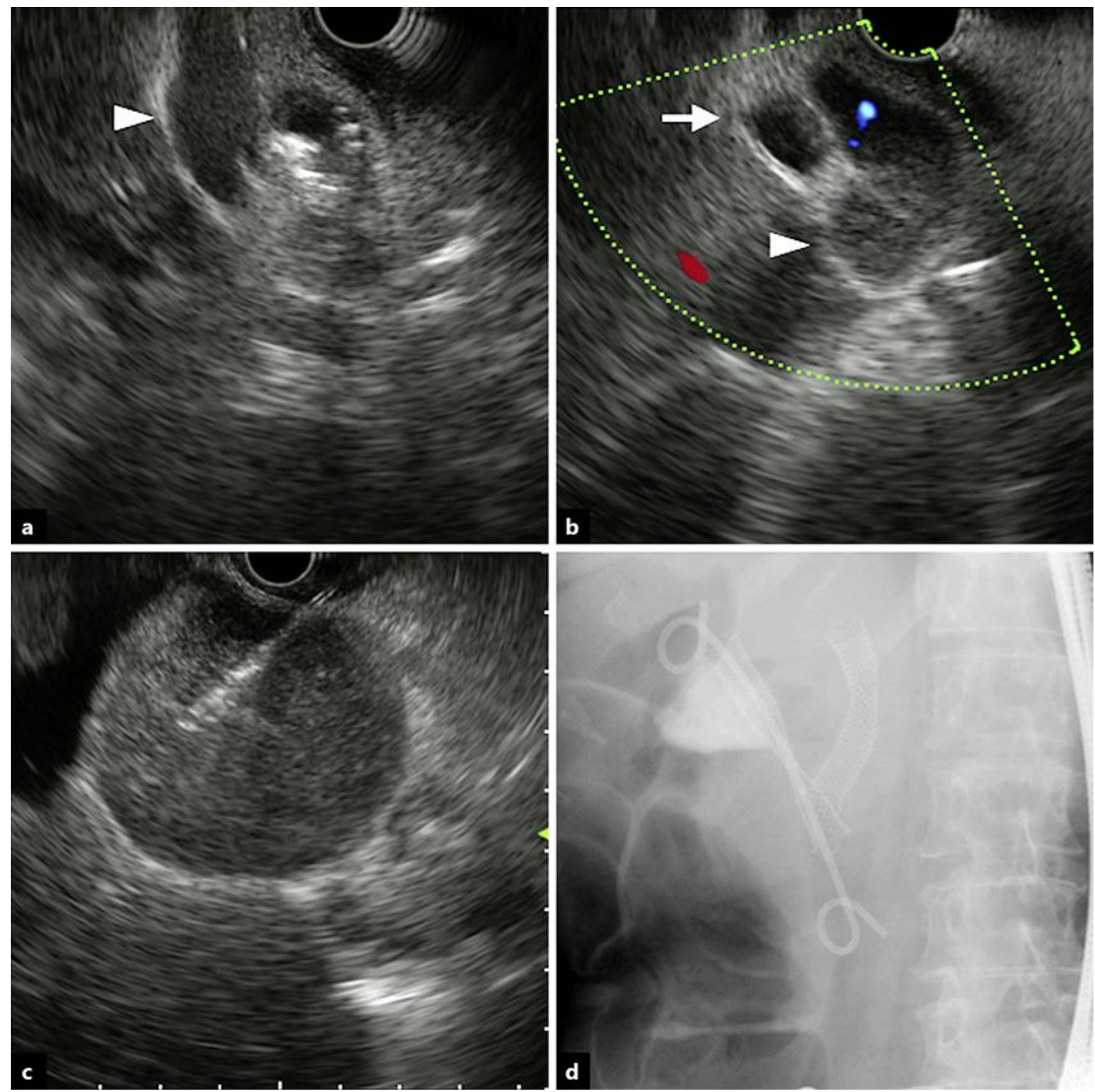

Fig. 2. Procedural steps of EUS-GBD. The cystic duct (arrowhead) is blocked by an indwelling covered SEMS placed for distal biliary obstruction (a). Both the cystic duct (arrowhead) and posterior intrahepatic duct (arrow) are dilated (b). The gallbladder is punctured with a 19-gauge EUS-FNA needle (c). A covered SEMS is introduced, with one indwelling pig-tail plastic stent placed though the SEMS, resulting in successful drainage of the infectious green bile (d). 


\section{Case Reports in Gastroenterology}

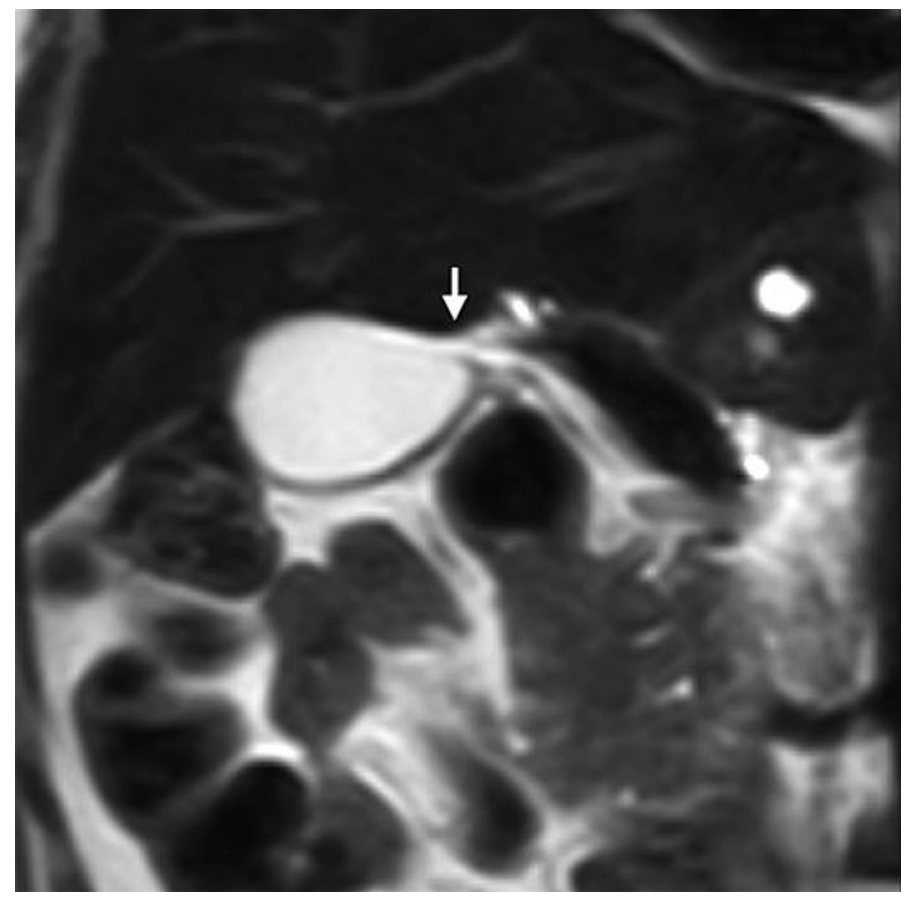

Fig. 3. Magnetic resonance imaging showing the AHD (cholecystohepatic duct). Confluence between the AHD and cystic duct (arrow).

Suzuki et al.: EUS-GBD for Aberrant Right Posterior Duct Obstruction Developing after Placement of a Covered SEMS in a Patient with Distal Biliary Obstruction

(c) 2018 The Author(s). Published by S. Karger AG, Basel www.karger.com/crg 